\title{
Corte Interamericana de Derechos Humanos y pueblos originarios. Lecturas desde la teoría de la justicia de Nancy Fraser $^{1}$
}

\section{The Inter-American Court of Human Rights and Indigenous People. Readings from Nancy Fraser's Theory of Justice}

\author{
Isabel Wences ${ }^{2}$ \\ Instituto Universitario de Estudios Latinoamericanos, \\ IELAT (España) \\ ORCID: https://orcid.org/0000-0001-5290-2733
}

Recibido: 19-12-2019

Aceptado: 07-07-2020

\section{Resumen}

En este artículo el objetivo es leer desde las premisas de la teoría tridimensional de la justicia de Nancy Fraser, que comprende distribución, reconocimiento y paridad política, la jurisprudencia más relevante de la Corte Interamericana de Derechos Humanos en materia de pueblos originarios. Para llevar a cabo esta tarea el texto se divide en dos partes. En la primera, se exponen los lineamientos del planteamiento de Nancy Fraser sobre la justicia y, en la segunda, se analiza,

\footnotetext{
${ }^{1}$ Este artículo se enmarca dentro del proyecto: "Teorías de la justicia y derecho global de los derechos humanos" (referencia PID2019-107172RB-I00), financiado por el Ministerio de Ciencia e Innovación de España.

2 (iwences@polsoc.uc3m.es) Coordinadora de la línea de investigación en ciencia y pensamiento político del Instituto Universitario de Estudios Latinoamericanos (IELAT) de la Universidad de Alcalá y miembro del Grupo de Investigación sobre el Derecho y la Justicia de la UC3M donde es Profesora Titular. Durante cinco años desempeñó el cargo de Subdirectora General de Estudios e Investigación del Centro de Estudios Políticos y Constitucionales. Entre sus publicaciones relacionadas con el tema del monográfico están La América de los Derechos (editado con Pablo Santolaya, Madrid: CEPC, 2016); "La Corte interamericana e il diritto alla propiedad comunal indígena: un' analisi nella prospettiva del riconoscimento e della diversità culturale" (en coautoría con Anna M. Russo, Diritto Pubblico Comparato ed Europeo, n. 3: 791-832, 2017); "La "discriminación de género" en la jurisprudencia de la Corte Interamericana de Derechos Humanos: hacia categorías y medidas transformativas" (en coautoría con MariaCaterina La Barbera, Andamios. Revista de investigación social, 17(42): 59-87, 2020).
} 
con base en las herramientas teórico políticas ofrecidas por esta pensadora, un conjunto de sentencias. Se concluye que la Corte IDH ha incorporado, en parte, esta perspectiva, aun cuando falta vigilar su implementación por parte de los Estados.

Palabras-clave: Justicia como redistribución, reconocimiento y representación; Derechos Humanos; Pueblos Indígenas.

\begin{abstract}
The objective of this article is to read the Inter-American Court of Human Rights' jurisprudence on original peoples in the three-dimensional theoretical framework of justice proposed by Nancy Fraser that includes distribution, recognition and participatory parity. In order to accomplish this task, the work is divided in two parts. In the first one, outlines of Nancy Fraser's approach on justice are exposed, and in the second one a set of sentences are analysed by means of those theoretical tools. The main conclusion lies in keeping that the IACtHR has partially incorporated this theoretical perspective notwithstanding there is a lack of monitoring its implementation by states.
\end{abstract}

Key-words: Justice as Redistribution, Justice as Recognition and Justice as Political Representation, Human Rights, Indigenous Peoples.

\title{
Encuentros en la intersección: Teoría Política y Derecho internacional de los Derechos Humanos. A manera de introducción
}

Los problemas urgentes -algunos inaplazables- a los que hoy en día debemos dar oportuna respuesta, en tanto investigadores responsables con nuestra sociedad, requieren en la gran mayoría de los casos de miradas transversales -sociales, económicas, ambientales, así como políticas y jurídicas-. Ello supone dejar atrás las aproximaciones ortodoxas que ciertas tendencias con fuerte presencia han conducido a nuestros campos de investigación al aislamiento, separándolos mediante "falsos" muros de formalismo y rígida especialización.

Esta separación ha hecho que, en concreto, la teoría política, las ciencias sociales y el Derecho público desarrollen por separado una parte relevante de sus programas de investigación, asumiendo muchas veces una suerte de acrítica división del trabajo que bajo la excusa de dar prioridad a evitar inexactitudes en discutibles tecnicismos, devalúa el interés de las preguntas planteadas y la validez argumental de las respuestas ofrecidas o, peor aún, lleva a que la selección de los problemas sobre los que diseñamos dichas preguntas estén mal 
o pobremente formuladas. Esto conlleva consecuencias contraproducentes para la investigación académica y -lo que es más importante- para los relevantes desafíos políticos que hoy en día tenemos por delante.

El estudio de problemas complejos como son la desigualdad, la pobreza, el desprecio, la sumisión y la violación de derechos, esto es, problemas relacionados con la justicia, requiere sin duda de la mirada de distintas perspectivas académicas. El respeto de la autonomía metodológica de cada campo disciplinar y la satisfacción de los criterios de rigor de cada uno de ellos son un instrumento para el estudio de esos problemas y no un fin en sí mismo.

De acuerdo con estos parámetros, el presente trabajo dirige su atención a leer desde una mirada filosófico política, la de Nancy Fraser, algunos fallos de la Corte Interamericana de Derechos Humanos (Corte IDH) de especial significación para la idea de justicia. Los casos elegidos centran su atención en los pueblos originarios, inmersos en una de las más graves y permanentes situaciones de injusticia del continente americano. En un informe de 2014 que no ha perdido vigencia, la Comisión Económica para América Latina (CEPAL) asevera que la región afronta una marcada heterogeneidad estructural, una vulnerabilidad extrema y persistentes niveles de desigualdad y confirma que "los pueblos indígenas integran precisamente los colectivos más desfavorecidos" (CEPAL, 2014: 5). Estos pueblos han sido históricamente discriminados tanto por el modelo distributivo que les ha confinado a la pobreza extrema como por la imposición de un modelo de uniformidad cultural basado en políticas de asimilación que les ha negado el reconocimiento de su identidad y diferencia.

La pregunta que me planteo es si esta serie de sentencias relativas a pueblos originarios puede ser analizada desde la propuesta tridimensional de la justicia de Fraser, que abarca distribución, reconocimiento y representación política. El trabajo se divide en dos partes. En la primera, expongo los grandes lineamientos del planteamiento de Nancy Fraser sobre la justicia y, en la segunda, analizo, con base en las herramientas teórico políticas ofrecidas por esta pensadora, un conjunto de sentencias.

\section{Lecturas desde la teoría política de Nancy Fraser: Justicia como distribución, justicia como reconocimiento y justicia como representación}

Cercana a la tradición de la teoría crítica de la sociedad ${ }^{3}$, Nancy Fraser es una investigadora que durante las últimas décadas ha reflexionado profundamente sobre la justicia. En su elaboración, ha llevado a cabo una

3 Definición programáticamente definida por Max Horkheimer en 1937 con el fin de distinguir la llamada teoría tradicional respecto de la que él y sus colegas del Instituto de Investigación Social de Frankfurt (entre ellos, Theodor W. Adorno) venían desarrollando, especialmente en el periodo de entreguerras.

Araucaria. Revista Iberoamericana de Filosofía, Política, Humanidades y Relaciones Internacionales, año $23, \mathrm{n}^{\circ} 46$. Primer cuatrimestre de 2021. Pp. 571-590. ISSN 1575-6823 e-ISSN 2340-2199 https://dx.doi.org/10.12795/araucaria.2021.i46.28 
reconstrucción del llamado pensamiento crítico de la sociedad y ha dado pasos hacia nuevas elaboraciones, inspirándose en las propuestas de la nueva izquierda posmarxista, los estudios culturales, poscoloniales y de género y, en general, deconstructivos, así como en Foucault, la fenomenología y el posestructuralismo ${ }^{4}$.

Desde una perspectiva metodológica, es posible sintetizar, de la mano de Carbonero y Valdivieso, los ejes que orientan sus estudios, cruzados generalmente por un enfoque de conflicto:

En primer lugar, su visión multidimensional de la dinámica social; en segundo lugar, su método dialógico y de democracia deliberativa para afrontar los retos de la práctica social; en tercer lugar, su visión histórica de las tensiones sociales y de la conformación de la teoría política; y, por último, su pragmatismo, o eclecticismo, entendido como la búsqueda en los debates de alternativas que impliquen soluciones efectivas en las prácticas de luchas emancipadoras (2011: 19).

Estos ejes se perciben constantemente en su libro Escalas de justicia (2008), donde plantea que la expresión inglesa "scales of justice" evoca dos imágenes. La primera es la tradicional imagen de la balanza que inspira luchas en pro de la justicia social y que da cuenta del equilibrio con que un juez imparcial sopesa los pros y contras de las reivindicaciones en conflicto. La segunda imagen, menos extendida, alude a un mapa, es decir, a un recurso a través del cual es posible representar proporcionalmente, igual que un geógrafo, relaciones espaciales. De acuerdo con la autora esta imagen, de impronta reciente para teorizar sobre la justicia, da cuenta de cómo las luchas de movimientos sociales objetan el marco nacional en el que se han situado históricamente los conflictos por la justicia; hoy en día, como consecuencia de la aceleración de la globalización, se ha transformado la escala de la interacción social y, por tanto, las cuestiones de la justicia deben diseñarse en una escala más amplia, deben ser "reenmarcadas", reinventadas, situadas a otra escala. La pensadora estadounidense considera que hay una heterogeneidad radical en el discurso sobre la justicia e insiste en que la globalización está cambiando nuestra forma de concebirla y de discutir sobre ella (Fraser, 2005).

Estas dos imágenes conllevan colosales desafíos para nuestras acostumbradas formas de pensar un mundo impregnado de injusticias. En cuanto a la balanza, el desafío procede de puntos de vista contrapuestos respecto del

${ }^{4}$ El testimonio de la propia Nancy Fraser da cuenta de ello: "Creo que la tarea de la teoría crítica es diagnosticar los tiempos que vivimos, identificar las principales formas de falta de libertad, de represión, explotación e injusticia, caracterizar las estructuras sociales y los mecanismos que generan esas injusticias, decir algo sobre las tensiones, conflictos y frentes en la sociedad y evaluar las perspectivas para un cambio social emancipador, todo esto da una especie de definición clásica de la teoría crítica en la que creo que no sólo cabe la Escuela de Frankfurt” (Fraser, 2008b: 92). 
"qué” de la justicia: ¿redistribución, reconocimiento o representación? Aquí, la cuestión a determinar es qué hay que considerar como asunto de justicia. En lo que al mapa se refiere, la dificultad surge de los enmarques conflictivos del "quién": ¿ciudadanías construidas con base en el territorio, humanidad global o comunidades de riesgo transnacionales? Aquí, la atención se dirige a quién cuenta como auténtico sujeto de justicia (Fraser, 2008a: 21). En consecuencia, "no es sólo la sustancia de la justicia la que entra en el debate, sino también el marco en el que se administra" (Fraser, 2005: 72).

A lo largo de varios de sus trabajos, esta profesora del New School for Social Research afronta el desafío de la balanza proponiendo una interpretación tridimensional del "qué" de la justicia, que abarca distribución en la esfera económica, reconocimiento en el campo sociocultural y representación en la dimensión política. En cuanto a la problemática del mapa, la autora se inclina por una teoría crítica del enmarque que tiene como objeto clarificar el "quién" se considera objeto de la justicia. Ello le lleva a reflexionar sobre quién debería contar con respecto a qué.

Estas cuestiones deben ser abordadas teorizando, desde los niveles de la filosofía moral, la teoría social y el análisis político, las relaciones entre las tres dimensiones fundamentales de la justicia antes citadas: distribución, reconocimiento y política. Como trasfondo de ello hay un empeño por comprender las estructuras, "diagnosticar las tensiones y contextualizar las luchas presentes” de la sociedad capitalista (Fraser y Honneth, 2006: 15).

Tanto la distribución como el reconocimiento, en perspectiva de Fraser, se acompañan de una referencia filosófica y de una política. Desde la perspectiva filosófica, ambas dimensiones constituyen paradigmas normativos, pero tienen orígenes y características distintos. Desde la perspectiva política, se refieren a conjuntos de reivindicaciones planteadas por actores políticos y movimientos sociales presentes en la esfera pública, pero diferenciados entre sí (Fraser, 2006).

La justicia como distribución tiene como objetivo fundamental una redistribución más justa de recursos, derechos, cargas, deberes y/o riqueza. $\mathrm{Su}$ atención está dirigida a las injusticias que resultan de la estructura socioeconómica (explotación, marginación) y la solución ante la injusticia supone una reestructuración económica (redistribución del ingreso o la riqueza, redistribución de la división del trabajo y reestructuración de la propiedad privada, entre otros). Por su parte, la justicia como reconocimiento también es una reivindicación de justicia social, pero a diferencia de la dimensión anterior busca tender vías para que se acepte y celebre la diferencia. El acento se encuentra puesto en las injusticias que derivan de la dominación cultural (sometimiento a determinados patrones de interpretación cultural, opacidad de las prácticas culturales, falta de respeto y menosprecio) y la solución ante este 
tipo de injusticia pasa por cambios en las valoraciones culturales (revaluación de subjetividades no respetadas y de sus producciones culturales; valoración de la diversidad cultural; entre otros) ${ }^{5}$.

Fraser considera que la justicia como distribución y la justicia como reconocimiento no deben comprenderse como esferas separadas, sino como esferas que se entrecruzan, se refuerzan mutuamente y en conjunto provocan consecuencias que se reproducen y propagan; hay divisiones sociales, subraya la pensadora, "arraigadas al mismo tiempo en la estructura económica y en el orden de estatus de la sociedad" (Fraser, 2006: 28) que implican injusticias relacionadas con una mala distribución y con un reconocimiento erróneo. Esta situación conduce a Fraser a concebir la reparación de las injusticias más allá de posibles arreglos de distribución más reconocimiento, porque desde su punto de vista hay que esforzarse por buscar soluciones políticas complejas donde sean considerados procesos de toma de decisión y deliberación democrática, y no caer en lo que ella denomina "malas soluciones" que pueden corregir la deficiente distribución, pero manteniendo un inadecuado reconocimiento o, viceversa, corregir el inadecuado reconocimiento pero dejando intacta la deficiente distribución o, incluso, llevar a soluciones en las que se reevalúen las identidades de grupos injustamente devaluadas pero dejando, sin embargo, sin alterar el contenido distributivo de estas identidades devaluadas.

Esta profesora, que comprende su quehacer intelectual como fruto del diálogo (además de debatir con Honneth, lo hace con Habermas, Benhabib, Young, Butler, Rorty, entre otros) y ha formulado relevantes aportaciones al feminismo, distingue entre soluciones transformativas y soluciones afirmativas entrelazadas tanto con la redistribución como con el reconocimiento. De esta manera, considera que son legítimas las reivindicaciones que buscan reestructurar las relaciones de producción para disipar la diferenciación entre los grupos, así como la reconstrucción de relaciones de reconocimiento mediante la deconstrucción de la cultura.

\footnotetext{
5 Nos llevaría excesivamente lejos abordar aquí el análisis pormenorizado del concepto de reconocimiento según la autora. Sin embargo, es útil significar que en su conceptualización no asocia el reconocimiento a la autorrealización - al alcance de la subjetividad plena y sin distorsiones- tal y como lo hacen Charles Taylor y Axel Honneth. Por el contrario, concibe el reconocimiento como un tema de justicia relacionado con el estatus social (lo llama modelo de estatus de reconocimiento). Creemos que el alejamiento de la estadounidense de la tradición hegeliana en la que participan los dos filósofos citados, apunta las bases teóricas de esta aproximación vinculada a la idea de estatus, lo que supone "examinar los patrones institucionalizados de valor cultural por sus efectos sobre el prestigio relativo de los actores sociales". Es un modelo de acuerdo con el cual el reconocimiento inadecuado se transmite mediante instituciones sociales, es decir, cuando las "instituciones estructuran la interacción de acuerdo con normas culturales que impiden la participación en pie de igualdad" (Fraser, 2006: 36). Estas normas culturales crean clases de personas con status devaluados (calificar a los gays de degenerados, a los afroamericanos de incumplidores de la ley, a los indígenas de ignorantes, y a los musulmanes de violentos).
} 
En su ensayo From Redistribution to recognition? Dilemmas of Justice in a "Postsocialist" Age señala que el dilema redistribución-reconocimiento, en una arena de múltiples y superpuestas luchas en las que los ejes de la injusticia se entrecruzan, es imposible de disolver o resolver por entero, pero que es necesario reflexionar sobre cómo afrontarlo. Desde su perspectiva, el reto de superar el círculo vicioso de subordinación cultural y económica que se refuerza mutuamente no puede remediarse a través de acciones afirmativas, porque éstas funcionan de manera aditiva y frecuentemente tienen propósitos cruzados. Por tanto, la vía de posibles soluciones debe generarse a través de acciones transformativas, "el proyecto de transformación de las estructuras profundas tanto de la economía política como de la cultura parece ser la única orientación programática global capaz de hacer justicia a todas las luchas actuales contra la injusticia" (Fraser, 1995:93).

Esta propuesta teórica que puso de relieve las dimensiones económica y cultural de la justicia, se vio reforzada con el paso del tiempo mediante la incorporación de la tercera dimensión, lo político ${ }^{6}$. Con esta dimensión, analíticamente distinta de la redistribución y el reconocimiento, Fraser "se refiere a la constitución de la jurisdicción del estado y de las reglas de decisión con las que éste estructura las disputas" (Fraser, 2005: 74). En consecuencia, la considera necesaria para explicar las injusticias en el plano de la política ordinaria que emergen cuando reglas de decisión sesgadas privan de voz política a personas, perjudicando su capacidad de participar como pares en la interacción social. Para alcanzar escenarios de justicia es necesario eliminar desigualdades sociales y desmantelar "los obstáculos institucionalizados que impidan que algunos participen en pie de igualdad" (Fraser, 2005: 72) y establecer condiciones de paridad participativa ${ }^{7}$. La justificación de la importancia de esta paridad participativa está relacionada con la necesidad de confinar dos diferentes tipos de injusticia: la deficiente distribución o injusticia distributiva y la falta de reconocimiento o desigualdad de estatus. El primer tipo se presenta cuando la plena participación de algunas personas se ve obstaculizada por estructuras económicas que impiden que cuenten con los medios necesarios para interactuar con los demás como iguales. El segundo tipo de injusticia que impide que las personas participen en condiciones de igualdad

\footnotetext{
${ }^{6}$ Esta apuesta por sumar lo político como una dimensión de la justicia es original y sumamente relevante. Muchos filósofos políticos lo han descuidado, subraya la pensadora estadounidense. No sólo los defensores del liberalismo y del comunitarismo, sino también los que suscriben la democracia deliberativa o el republicanismo, quienes en su defensa de lo político como una premisa importante no lo han conceptualizado como una dimensión de la justicia (Fraser, 2005).

${ }^{7}$ El término paridad, acuñado por Fraser (1990), ha logrado notables alcances en la política y en las reivindicaciones feministas. Sin embargo, los significados han ido transformándose y lo que hoy en día en muchos discursos políticos se designa como igualdad numérica estricta de género en la representación política, no es la idea original de Fraser para quien la paridad es un requisito moral que significa "la condición de ser un igual, de estar a la par con los demás, de estar en pie de igualdad" (Fraser, 2006: 42).
} 
se presenta cuando existen jerarquías institucionalizadas de valor cultural que niegan un reconocimiento adecuado (Fraser, 2005). Queda claro, entonces, que lo político establece el escenario donde se llevan a cabo las batallas sobre la distribución y el reconocimiento.

La consideración de lo político como una dimensión de la justicia enriquece, por un lado, la comprensión del "qué" de la justicia porque ayuda a apreciar la relativa autonomía de las desigualdades enraizadas en la constitución política de la sociedad. Por el otro, es de utilidad para explicar las injusticias que surgen cuando la división del espacio político provoca un enmarque injusto de las cuestiones centrales de la distribución y el reconocimiento. La dimensión política de la justicia especifica el alcance de las otras dimensiones ya que nos indica quién queda incluido y quién queda excluido de la distribución y del reconocimiento.

En otras palabras, Fraser se cuestiona hasta qué punto las exigencias de la justicia pueden ser desentrañadas mientras no nos preguntemos sobre la especificidad de lo político, sobre quiénes son los partícipes relevantes, ya sea que se trate de ajustes estructurales, demandas por la tierra, inmigración y refugio, calentamiento global y generaciones futuras, violencia de género o matrimonio homosexual; qué asuntos son genuinamente locales, regionales, nacionales o globales y a través de qué tipo de procesos de toma de decisiones se conforman y definen.

Esta idea de lo político, centrada en cuestiones de jurisdicción y procedimiento, conduce a que la dimensión política de la justicia se encuentre directamente relacionada con la idea de representación. Por una parte, fija los criterios de pertenencia y determina con ello la inclusión o exclusión de los individuos y su derecho a la justa distribución y al reconocimiento. Por otra parte, la dimensión política, al determinar reglas de decisión, establece los procedimientos para la presentación y resolución de los enfrentamientos, tanto económicos como culturales. La pensadora estadounidense pone como ejemplo de quién puede reivindicar redistribución y reconocimiento y de cómo se deben confeccionar y encausar tales reivindicaciones, la cuestión de catalogar injusticias transnacionales como si fueran asuntos meramente nacionales y cuando esto sucede el "quién" de la justicia se encuentra a sí mismo definido injustamente, dado que en estos casos el individuo se encuentra afectado por estructuras tanto extraterritoriales como no territoriales ${ }^{8}$. Ella subraya constantemente que la globalización incrementa la brecha entre la territorialidad del Estado y la efectividad social. Piénsese, por ejemplo, en las reivindicaciones de la población pobre del mundo que es relegada a ámbitos políticos internos de Estados débiles o fallidos impidiéndoseles con

8 Vid. Thomas W. Pogge (2002), World and Poverty and Human Rights: Cosmopolitian Responsabilities and Reforms, Cambridge: Polity Press.

Araucaria. Revista Iberoamericana de Filosofia, Política, Humanidades y Relaciones Internacionales, año $23, \mathrm{n}^{\circ} 46$. Primer cuatrimestre de 2021. Pp. 571-590. ISSN 1575-6823 e-ISSN 2340-2199 https://dx.doi.org/10.12795/araucaria.2021.i46.28 
ello oponerse a las fuentes externas de su condición de desposeídos (Fraser, 2008a).

El corpus teórico de Fraser, resumido en las páginas anteriores, puede ser un mapa que nos oriente a la hora de observar si operadores jurídicos encargados de defender derechos humanos contemplan esta aportación teórica de las distintas dimensiones de la justicia o se limitan a comprenderla, en una línea más tradicional, tan sólo desde una perspectiva distributiva.

\section{Lecturas de la jurisprudencia en perspectiva de Fraser}

En este apartado me centraré en observar algunos de los fallos de la Corte IDH con el fin de detectar si encontramos en ellos reflexiones que apunten al desarrollo de la idea de justicia incrementando su complejidad en la línea de los principios que apunta Fraser con su teoría tridimensional. Para ello, dirijo la atención únicamente a casos relacionados con pueblos originarios ya que estos colectivos han sido sistemáticamente relegados a la pobreza, sufriendo injusticia socioeconómica; menospreciados desde la época colonial, padeciendo un trato injusto desde una perspectiva cultural; y arrinconados de los procesos de toma de decisiones políticas ${ }^{9}$. En consecuencia, suelen ser de los colectivos más necesitados de una política redistributiva, de un reconocimiento de la diversidad cultural y de la instauración de mecanismos que permitan su participación en igualdad de condiciones. Las preguntas que recorren el presente apartado son: $¿$ es posible encontrar en estas sentencias dimensiones tanto distributivas como de reconocimiento? ¿se aprecian en ellas alusiones a la dimensión política? Para responder a estas cuestiones, se han seleccionado las sentencias centradas en pueblos originarios: Comunidad Mayagna de Awas Tingni Vs. Nicaragua (2001), Caso Comunidad Indigena Yakye Axa Vs. Paraguay (2005), Caso Comunidad Indigena Sawhoyamaxa Vs. Paraguay (2006), Caso Comunidad Indígena Xákmok Kásek Vs. Paraguay (2010), Caso Pueblo Indígena Kichwa de Sarayaku Vs. Ecuador (2012), Caso Comunidad Garífuna Triunfo de la Cruz y sus Miembros Vs. Honduras (2015); y Caso Pueblos Kaliña y Lokono Vs. Surinam $(2015)^{10}$. En todos estos casos, la Corte IDH se refiere a barreras

\footnotetext{
${ }^{9}$ Los casos de la violación de derechos de otros colectivos también podrían ser analizados desde la teoría tridimensional de Fraser. A título de ejemplo podrían mencionarse, entre otros: Caso González y otras (Campo Algodonero) VS. México de 16 de noviembre de 2009 o Caso Atala Riffo y niñas VS. Chile de 24 de febrero de 2012. Véase para ello La Barberá y Wences (2020).

${ }^{10}$ Corte IDH. Caso de la Comunidad Mayagna (Sumo) Awas Tingni Vs. Nicaragua. Fondo, Reparaciones y Costas. Sentencia de 31 de agosto de 2001. Serie C No. 79; Corte IDH. Caso Comunidad Indigena Yakye Axa Vs. Paraguay. Fondo Reparaciones y Costas. Sentencia 17 de junio de 2005. Serie C No. 125; Corte IDH. Caso Comunidad Indigena Sawhoyamaxa Vs. Paraguay. Fondo, Reparaciones y Costas. Sentencia de 29 de marzo de 2006. Serie C No. 146; Corte IDH. Caso Comunidad Indígena Xákmok Kásek Vs. Paraguay. Fondo, Reparaciones y Costas. Sentencia de 24 de agosto de 2010. Serie C No. 214; Corte IDH. Caso Pueblo Indigena Kichwa de Sarayaku
} 
estructurales que obstaculizan el acceso a la justicia de los pueblos originarios e impiden la presencia de condiciones de existencia digna.

Dos son los ejes sobre los que se construye la argumentación. En primer lugar, observando a qué se refiere la Corte con condiciones de existencia digna y examinando las medidas de reparación y de obligaciones impuestas para los Estados. Y, en segundo lugar, observando si el Tribunal Interamericano se muestra sensible a la diversidad cultural.

Con la primera de las sentencias mencionadas, el leading case Awas Tingni Vs. Nicaragua, la Corte IDH imprimió una importante huella en el proceso de reconocimiento y de aplicación de los derechos humanos de los pueblos originarios, especialmente del derecho a la tierra, al territorio y a los recursos naturales; y en los subsiguientes fallos fue fortaleciendo este reconocimiento junto con la adopción de medidas de reparación de carácter distributivo y de imposición de obligaciones para los Estados como, por ejemplo, la creación de un fondo de desarrollo comunitario.

A mediados de la década de los 90 una pequeña, pobre y aislada comunidad indígena de la Costa Atlántica de Nicaragua, la comunidad Awas Tingni del pueblo Mayangna acudió a la Comisión Interamericana de Derechos Humanos (CIDH) para denunciar al Gobierno nicaragüense por haber realizado concesiones para la explotación de madera en el territorio ancestral de la comunidad sin su consentimiento y alegando que se trataba de tierras de libre disposición por parte de Estado. La Comisión, ante el continuo incumplimiento de sus recomendaciones por parte del gobierno nicaragüense, envió en 1998 el caso a la Corte IDH.

El Tribunal Interamericano dictó sentencia el 31 de agosto de 2001, fallando a favor de la comunidad Awas Tingni, los jueces estimaron que "dadas las características del presente caso, es menester hacer algunas precisiones respecto del concepto de propiedad en las comunidades indígenas. Entre los indígenas existe una tradición comunitaria sobre una forma comunal de la propiedad colectiva de la tierra, en el sentido de que la pertenencia de ésta no se centra en un individuo sino en el grupo y su comunidad. Los indígenas por el hecho de su propia existencia tienen derecho a vivir libremente en sus propios territorios; la estrecha relación que los indígenas mantienen con la tierra debe de ser reconocida y comprendida como la base fundamental de sus culturas, su vida espiritual, su integridad y su supervivencia económica. Para las comunidades indígenas la relación con la tierra no es meramente una cuestión

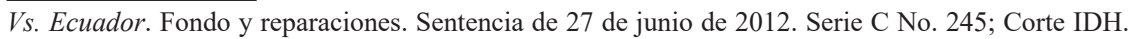
Caso Comunidad Garifuna Triunfo de la Cruz y sus Miembros Vs. Honduras. Fondo, Reparaciones y Costas. Sentencia de 08 de octubre de 2015. Serie C No. 305; Corte IDH. Caso Pueblos Kalina y Lokono Vs. Surinam. Fondo, Reparaciones y Costas. Sentencia de 25 de noviembre de 2015. Serie C No. 309. Una reciente sentencia que podría también incluirse en este listado, caso comunidades indígenas miembros de la asociación Lhaka Honhat (nuestra tierra) vs. Argentina de 6 febrero del 2020, es tratada con detenimiento por Digno Montalván en este mismo número monográfico.

Araucaria. Revista Iberoamericana de Filosofia, Política, Humanidades y Relaciones Internacionales, año $23, \mathrm{n}^{\circ} 46$. Primer cuatrimestre de 2021. Pp. 571-590. ISSN 1575-6823 e-ISSN 2340-2199 https://dx.doi.org/10.12795/araucaria.2021.i46.28 
de posesión y producción, sino un elemento material y espiritual del que deben gozar plenamente, inclusive para preservar su legado cultural y transmitirlo a las generaciones futuras" (párr. 149) ${ }^{11}$.

La interpretación dada por la Corte Interamericana al derecho de propiedad en este caso ha constituido un auténtico desafío a la concepción tradicional del derecho de propiedad que figura en los más relevantes instrumentos internacionales de derechos humanos. A partir de este caso, con el que se inicia el largo ciclo de sentencias sobre el problema de la demarcación y titulación de los territorios, la Corte IDH reconoce la existencia de un derecho a la "propiedad comunal" de los pueblos originarios sobre las tierras que tradicionalmente han ocupado - tal y como viene definida por sus usos y costumbre-, amparado por el art. 21 de la Convención Americana de Derechos Humanos (CADH). La Corte siguió lo que ella misma denominó un método evolutivo de interpretación -una interpretación creativa- de la CADH para que su ámbito de protección pueda abarcar también un concepto "ancestral" de propiedad y no solo el estrictamente formal y ortodoxo derecho de propiedad entendido como derecho individual ${ }^{12}$. Esta interpretación es realizada a través de una perspectiva universalista anclada en fundamentos convencionales puntuales (arts. 1.1, 2, $29 \mathrm{CADH}$ ) que le permite abordar el tema recurriendo a desarrollos normativos en materia de derechos humanos producidos en contextos de derecho internacional distintos al sistema interamericano.

La relevancia de la sentencia queda bien expuesta por Rodolfo Stavenhagen cuando señala que ésta "marcó un parteaguas en el derecho internacional indígena porque subraya, por primera vez, la estrecha relación entre los derechos humanos individuales y colectivos de los pueblos indígenas con respecto al derecho de propiedad de la tierra" (Stavenhagen, 2010: 69) ${ }^{13}$.

11 Altamente significativo es el voto razonado concurrente del Juez Sergio García Ramírez a esta
Sentencia, al establecer: "En el análisis del tema sujeto a su jurisdicción, la Corte Interamericana
contempló los derechos de uso y goce reconocidos en el artículo 21 desde la perspectiva, perfectamente
válida, de los miembros de las comunidades indígenas. En mi concepto, esta forma de analizar el
tema, para los fines de la presente Sentencia, no implica en modo alguno desconocer o negar derechos
de otra naturaleza o alcance vinculados con aquéllos, como son los de carácter colectivo, a los que con
la mayor frecuencia aluden las normas e instrumentos nacionales e internacionales que he invocado
en este voto. Es indispensable observar que estos derechos comunitarios, que forman parte entrañable
de la cultura jurídica de muchos pueblos indígenas, y por lo tanto de sus integrantes, constituyen la
fuente y el amparo de los derechos subjetivos individuales. En suma, existe una íntima e indisoluble
vinculación entre los derechos de ambos órdenes -individuales y colectivos-, de cuya vigencia efectiva
depende la genuina tutela de las personas que forman parte de los grupos étnicos indígenas" Corte
IDH. Voto particular concurrente del Juez Sergio García Ramírez al Caso de la Comunidad Mayagna
(Sumo) Awas Tingni Vs. Nicaragua. Sentencia de 31 de agosto de 2001 . Serie C No. 79. párr. 14.
12 En una sentencia posterior señaló que el "derecho al territorio" debe abarcar "la totalidad de la
tierra y los recursos naturales que los pueblos indígenas y tribales han utilizado tradicionalmente"
(Corte IDH. Caso del Pueblo Saramaka. VS. Surinam. Excepciones Preliminares, Fondo, Reparaciones
y Costas. Sentencia de 28 de noviembre de 2007 . Serie C No. 172, párr. 82, nota al pie n. 63).
13 Así queda expresado también en el voto razonado concurrente del Juez Sergio García Ramírez:
"El tema de esta Sentencia, y por ende ella misma, se sitúa en un punto de convergencia entre derechos 
Con el reconocimiento de la estrecha relación entre la tierra, la identidad y la cultura de los pueblos originarios, este Tribunal Interamericano abre su mirada al derecho a la diferencia de las comunidades indígenas, mediante el reconocimiento de una identidad cultural diferenciada, cuya especificidad se deriva de la trascendental interrelación de los pueblos originarios con la tierra, el territorio y los recursos naturales. Con este caso, la Corte IDH inicia el desarrollo de una interesante línea jurisprudencial orientada a ampliar el marco jurídico tradicionalmente liberal de la Convención Americana de Derechos Humanos. Resulta también particularmente relevante que en los marcos jurídicos de matriz liberal configurados por la tradicional preeminencia de los derechos del individuo, la Corte IDH haya dado pasos significativos para el reconocimiento de los derechos de las comunidades, es decir de los derechos de la colectividad (Russo y Wences, 2016).

Para ilustrar cómo se ha ido robusteciendo este reconocimiento, tanto del derecho a una identidad diferenciada como del derecho colectivo a la propiedad, reproducimos aquí algunos párrafos de otras sentencias. En los tres casos contra Paraguay, el Tribunal Interamericano se refiere al impacto de la identidad cultural en el proceso interpretativo. En el caso Yakye Axa, la Corte considera que es oportuno recordar que los Estados "deben tomar en consideración las características propias que diferencian a los miembros de los pueblos indígenas de la población en general y que conforman su identidad cultural" (párr. 51) y más adelante señala que "en lo que respecta a pueblos indígenas, es indispensable que los Estados otorguen una protección efectiva que tome en cuenta sus particularidades propias, sus características económicas y sociales, así como su situación de especial vulnerabilidad, su derecho consuetudinario, valores, usos y costumbres" (párr. 63) ${ }^{14}$. Unos años más tarde, en 2012, en el caso Kichwa de Sarayaku Vs. Ecuador, la Corte da un paso adelante y reconoce claramente que "el derecho a la identidad cultural es un derecho fundamental y de naturaleza colectiva de las comunidades indígenas, que debe ser respetado en una sociedad multicultural, pluralista y democrática. Esto implica la obligación de los Estados de garantizar a los pueblos indígenas que sean debidamente consultados sobre asuntos que inciden o pueden incidir en su vida cultural y social, de acuerdo con sus valores, usos, costumbres y formas de organización" (párr. 217). Asimismo, de acuerdo con su interpretación del artículo 21 de la CADH, el Tribunal Interamericano afirma, en este mismo caso, que este artículo "protege la vinculación estrecha que los pueblos indígenas guardan con sus tierras, así como con los recursos naturales de los territorios

civiles y derechos económicos, sociales y culturales" (párr. 17)

${ }^{14}$ En este mismo sentido se pronuncia el Tribunal en otras sentencias. Véanse particularmente: Caso Comunidad Indígena Sawhoyamaxa Vs. Paraguay, párr. 83; Caso del Pueblo Saramaka. Vs. Surinam, párr. 178; Caso Pueblo Indigena Kichwa de Sarayaku Vs. Ecuador, párr. 264; Caso de los Pueblos Indigenas Kuna de Madungandi y Emberá de Bayano y sus Miembros Vs. Panamá, párr. 167. 
ancestrales y los elementos incorporales que se desprendan de ellos. Entre los pueblos indígenas existe una tradición comunitaria sobre una forma comunal de la propiedad colectiva de la tierra, en el sentido de que la pertenencia de ésta no se centra en un individuo sino en el grupo y su comunidad. Estas nociones del dominio y de la posesión sobre las tierras no necesariamente corresponden a la concepción clásica de propiedad, pero merecen igual protección del artículo 21 de la Convención Americana. Desconocer las versiones específicas del derecho al uso y goce de los bienes, dadas por la cultura, usos, costumbres y creencias de cada pueblo, equivaldría a sostener que sólo existe una forma de usar y disponer de los bienes, lo que a su vez significaría hacer ilusoria la protección de tal disposición para millones de personas" (párr. 145).

Todas las referencias anteriores dan cuenta de la interpretación "culturalmente sensible" (Nash Rojas, 2014) que desarrolla la Corte para garantizar el goce efectivo de los derechos y libertades de las comunidades indígenas, en condiciones de no discriminación e igualdad diferenciada. Aunque en estas páginas son breves las citas de las sentencias mencionadas, las referencias dejan una clara constancia "de la labor creativa de la Corte IDH en la construcción de un corpus iuris amplio que hace hincapié en una interpretación dinámica del art. $21 \mathrm{CADH}$, a través de la cual el juez asigna a la norma citada contenidos culturales inherentes para adaptarlo al contexto especifico de los pueblos indígenas y a sus demandas" (Russo y Wences, 2016).

Ahora bien, la garantía del derecho a la identidad cultural y con él del reconocimiento de una forma de entender la propiedad requeriría, de acuerdo con la propuesta de Fraser, de la puesta en marcha de cambios estructurales que combatan las causas de las injusticias socioeconómicas. En consecuencia, solo es posible encontrar las dimensiones de la justicia planteadas por Nancy Fraser si en estas sentencias la alusión al establecimiento de condiciones de existencia digna está relacionada también con planteamientos redistributivos. Así lo expresan dos estudiosos argentinos que han escrito sobre esta misma línea temática: "sólo son respetuosas de los derechos de los pueblos originarios aquellas soluciones que implican una mejor distribución de los bienes económicos y sociales, pero que a su vez los incluyen en el proceso de toma de decisiones y se tenga en cuenta su interpretación de sus necesidades, intereses y proyectos como comunidad" (Clérico y Aldao, 2011: 159).

La situación de extrema pobreza en la que viven gran parte de los pueblos originarios está directamente relacionada con la falta de acceso a la propiedad comunitaria de sus tierras y esta circunstancia supone la presencia de grandes obstáculos para el autoabastecimiento y la autosostenibilidad. Dado que "el vínculo de los miembros de la Comunidad con sus territorios es fundamental e inescindible para su supervivencia alimentaria y cultural" la Corte establece 
la "importancia de su devolución" (Caso Comunidad Indígena Xákmok Kásek Vs. Paraguay, párr. 82).

Además de la exigencia de restitución de las tierras, para generar condiciones que garanticen derechos a la vida digna de las comunidades el Tribunal Interamericano ha dispuesto tanto obligaciones para los Estados como medidas de reparación relacionadas con los derechos de acceso al agua, alimentación, salud y educación ${ }^{15}$. En cuanto a lo primero, la Corte señala que los Estados deben generar condiciones de vida mínimas compatibles con la dignidad de la persona humana. Esto supone adoptar medidas positivas apropiadas y relacionadas con los artículos 10 (Derecho a la Salud); 11 (Derecho a un Medio Ambiente Sano); 12 (Derecho a la Alimentación); 13 (Derecho a la Educación) y 14 (Derecho a los Beneficios de la Cultura) del Protocolo Adicional a la Convención Americana en materia de Derechos Económicos, Sociales y Culturales, y las disposiciones pertinentes del Convenio No. 169 de la OIT" (Caso Comunidad Indigena Yakye Axa Vs. Paraguay, párr. 163).

Asimismo, desde el Caso Yakye Axa hasta los casos más recientes en materia de pueblos originarios, el Tribunal Interamericano ha ordenado sistemáticamente la creación de un "fondo de desarrollo comunitario" como compensación por el daño material e inmaterial que los miembros de la comunidades han sufrido, subrayando su carácter de "medida adicional" a cualquier otra disposición que subsane a las comunidades en relación con los deberes generales del Estado (Caso Garífuna Triunfo de La Cruz, párr. 295). Este fondo de desarrollo comunitario consiste en implementar proyectos educativos, habitacionales, agrícolas y de salud.

En relación a las medidas de reparación, a título de ejemplo podemos citar la sentencia del caso Xákmok Kásek donde la Corte dispone que se suministren bienes y servicios elementales en materia de alimentación, sanidad y educación. Pormenoriza así la Corte: “(...) mientras se entrega el territorio tradicional, o en su caso las tierras alternativas, a los miembros de la Comunidad, el Estado deberá adoptar de manera inmediata, periódica y permanente, las siguientes medidas: a) suministro de agua potable suficiente para el consumo y aseo personal de los miembros de la Comunidad; b) revisión y atención médica y psicosocial de todos los miembros de la Comunidad, especialmente los niños, niñas y ancianos, acompañada de la realización periódica de campañas de vacunación y desparasitación que respeten sus usos y costumbres; c) atención médica especial a las mujeres que se encuentren embarazadas, tanto antes del parto como durante los primeros meses después de éste, así como al recién nacido; d) entrega de alimentos en calidad y cantidad suficientes para asegurar

${ }^{15}$ La función reparativa en la jurisprudencia de la Corte IDH es de suma relevancia y junto con la facultad de supervisión del cumplimiento de las sentencias y de las medidas de reparación y monitoreo de la debida implementación, constituyen un rasgo distintivo de este tribunal (Calderón Gamboa, 2103).

Araucaria. Revista Iberoamericana de Filosofia, Política, Humanidades y Relaciones Internacionales, año $23, \mathrm{n}^{\circ} 46$. Primer cuatrimestre de 2021. Pp. 571-590. ISSN 1575-6823 e-ISSN 2340-2199 https://dx.doi.org/10.12795/araucaria.2021.i46.28 
una alimentación adecuada; e) instalación de letrinas o cualquier tipo de servicio sanitario adecuado en el asentamiento de la Comunidad, y f) dotar a la escuela de los materiales y recursos humanos necesarios para garantizar el acceso a la educación básica para los niños y niñas de la Comunidad, prestando especial atención a que la educación impartida respete sus tradiciones culturales y garantice la protección de su lengua propia. Para tales efectos, el Estado deberá realizar las consultas que sean necesarias a los miembros de la Comunidad" (párr. 301) ${ }^{16}$.

Esta última frase da cuenta también de que la Corte prescribe, de manera similar a otros organismos como la Organización Internacional del Trabajo - Convenio 169- y organismos internacionales como las Naciones Unidas con su Declaración Universal sobre los Derechos de los Pueblos Indígenas, el derecho a la consulta de los pueblos originarios y la necesaria obtención de su consentimiento libre, previo e informado, de acuerdo con sus costumbres y tradiciones, cuando se trata de planes de desarrollo o de inversión en sus territorios. Esto supone el desmantelamiento de "obstáculos institucionalizados que impidan que algunos participen en pie de igualdad" (Fraser, 2005: 72) y el establecimiento de garantías fundamentales para que los pueblos y comunidades indígenas puedan participar "en las decisiones relativas a medidas que afecten sus derechos, y en particular su derecho a la propiedad comunal" (Caso Pueblo Indigena Kichwa de Sarayaku Vs. Ecuador, párr. 160).

Así, el derecho a la consulta además de constituir una norma convencional es un principio general del Derecho Internacional que obliga a los Estados a realizar procesos de consulta de carácter especial y diferenciado cuando estén concernidos intereses de las comunidades y de los pueblos originarios. Asimismo, implica dejar claras las "reglas de decisión" con las que se "estructuran las disputas" (Fraser, 2005: 74), es decir, implica el deber de organizar de manera adecuada las estructuras del aparato gubernamental a través de las cuales se manifiesta el ejercicio del poder público con el fin de quede asegurado jurídicamente el libre y pleno ejercicio de los derechos.

No sólo presenciamos aquí dispositivos propios de una dimensión de paridad participativa, sino además de la justicia como reconocimiento dado que estas prácticas deben llevarse a cabo mediante "procedimientos culturalmente adecuados" que respeten "el sistema particular de consulta de cada pueblo o comunidad", es decir, que deben desarrollarse "de conformidad con sus propias tradiciones" y "tomando en cuenta los métodos tradicionales del pueblo para la

${ }^{16}$ En este mismo sentido véanse las sentencias: Caso Comunidad Yakye Axa Vs. Paraguay, párr. 221; Caso Comunidad Indígena Sawhoyamaxa Vs. Paraguay, párr. 224; Caso Comunidad Garifuna Triunfo de la Cruz y sus Miembros Vs. Honduras, párr. 296. 
toma de decisiones" (Caso Pueblo Indigena Kichwa de Sarayaku Vs. Ecuador, párr. 77 y 65).

Toda la exposición anterior da cuenta de que las dimensiones de la justicia como distribución, como reconocimiento y como paridad participativa han sido incorporadas por la Corte IDH en su jurisprudencia. Ahora bien, "las sentencias no significan el final de los procesos sino que son simplemente un punto y seguido de un largo proceso en el que por supuesto juega un papel determinante pero no definitivo, ya que sin su ejecución la sentencia queda en simples palabras" (Berraondo, 2004: 67 y 68). Por tanto, es necesario vigilar que esta jurisprudencia sea reconocida e implementada por los tribunales nacionales y las instituciones públicas domésticas.

\section{Conclusiones}

A lo largo del texto he, por un lado, bosquejado algunas pinceladas de las aportaciones teóricas de Fraser con el fin de comprender, en el marco de su empeño por rehabilitar la teoría crítica, sus reflexiones sobre la justicia; y, por el otro, he intentado leer desde sus premisas de distribución, reconocimiento y paridad política la jurisprudencia más relevante de la Corte IDH en materia de pueblos originarios.

Considero que recuperar el pensamiento de Nancy Fraser puede ofrecer luz a los operadores jurídicos estatales e internacionales responsables de proteger los derechos humanos, especialmente cuando los casos se enmarcan en contextos de desigual distribución socioeconómica e inadecuado reconocimiento cultural.

Muchos autores sostienen que la reivindicación de la diferencia cultural no tiene la misma importancia que la demanda de la igualdad ${ }^{17}$. Sin embargo, caen en la extendida confusión de la diferencia con la desigualdad sin percatarse de que ambos términos no son discordantes, sino que la diferencia es un derecho y la desigualdad una condición que es imperioso extirpar (Bartolomé, 2008). Si observamos las demandas de los pueblos originarios observamos que reclaman, al mismo tiempo, el derecho a la igualdad económica y social, por una parte, y la reivindicación del reconocimiento de su diferencia cultural, por la otra. Esto supone que la garantía del derecho a la diferencia debe acompañarse de la puesta en marcha de cambios estructurales que combatan las causas de las discriminaciones, exclusiones y desigualdades causadas por condiciones socioeconómicas (Wences, 2016).

Por último, me gustaría cerrar señalando que el marco teórico que presenta Nancy Fraser para hacer frente a las cuestiones de (in)justicia constituye una

${ }^{17}$ Una explicación más pausada sobre este debate puede encontrarse en (Sauca, 2010: 11-15 y 23-38).

Araucaria. Revista Iberoamericana de Filosofia, Política, Humanidades y Relaciones Internacionales, año $23, \mathrm{n}^{\circ} 46$. Primer cuatrimestre de 2021. Pp. 571-590. ISSN 1575-6823 e-ISSN 2340-2199 https://dx.doi.org/10.12795/araucaria.2021.i46.28 
aportación teórico-práctica de utilidad dado que nos ofrece herramientas para afrontar los dilemas, tensiones y conflictos latentes en la estructura social. Con la mirada siempre puesta en el reto de la justicia social y con una orientación crítica de las sociedades capitalistas ha articulado, con ambición intelectual, una concepción normativa de la justicia, de carácter tridimensional, que puede servir de brújula a la hora de articular pragmáticamente respuestas teóricas a las demandas de justicia de nuestras actuales sociedades. 


\section{Bibliografía:}

Bartolomé, Miguel Alberto, Procesos interculturales. Antropología política del pluralismo cultural en América Latina, México, Siglo XXI, 2008.

Berraondo, Mikel, "Lecciones del Caso Awas Tingni tres años después de la sentencia de la Corte Inter-Americana", en Pueblos en Lucha. Casos emblemáticos de defensa de derechos indígenas, Quito, FLACSO, 2004.

Calderón Gamboa Jorge F., La evolución de la "reparación integral” en la jurisprudencia de la Corte interamericana de derechos humanos, México D.F., Comisión Nacional de los Derechos Humanos, 2013.

Carbonero Gamundí, Ma . Antònia y Valdivieso, Joaquín, “Introducción. Nancy Fraser y la nueva teoría crítica de la sociedad", en $\mathrm{M}^{\mathrm{a}}$. Antònia Gamundi y Joaquín Valdivieso (eds.), Dilemas de la justicia en el siglo XXI. Género y globalización de Nancy Fraser, Palma (España), Universitat de les Iles Balears, 2011.

Clérico, Laura y Martín Aldao, "Nuevas miradas de la igualdad en la jurisprudencia de la Corte Interamericana de Derechos Humanos: la igualdad como redistribución y como reconocimiento", Lecciones y Ensayos, n. 89 (2011), pp. 141-179.

Comisión Económica para América Latina (CEPAL), Los pueblos indígenas en América Latina. Avances en el último decenio y retos pendientes para la garantía de sus derechos, Santiago (Chile), Naciones Unidas, 2014.

Fraser, Nancy, "Rethinking the Public Sphere: A Contribution to the Critique of Actually Existing Democracy" Social Text, n. 25/26 (1990), pp. 56-80.

Fraser, Nancy, "From Redistribution to recognition? Dilemmas of Justice in a "Postsocialist" Age", New Left Review, n. 212 (1995), pp. 68-93.

Fraser, Nancy, "Redefiniendo el concepto de justicia en un mundo globalizado", Anales de la Cátedra Francisco Suárez, n. 39 (2005), pp. 69-87.

Fraser, Nancy, "La justicia social en la era de la política de la identidad: redistribución, reconocimiento y participación”, en Nancy Fraser y Axel Honneth, ¿Redistribución o reconocimiento? Un debate político filosófico, Madrid, Morata, 2006.

Fraser, Nancy, Escalas de justicia, Barcelona, Herder, 2008a.

Fraser, Nancy, "Against Pollyanna-ism: A Reply to Iris Young”, en Kevin Olson (ed.), Adding Insult to Injury: Nancy Fraser Debats her Critics: Debating Redistribution, Recognition and Representation, London, Verso, $2008 \mathrm{~b}$.

Fraser, Nancy y Axel Honneth, ¿Redistribución o reconocimiento? Un debate político filosófico, Madrid, Morata, 2006.

Gómez Isa, Felipe, “El derecho de los pueblos indígenas sobre sus tierras y recursos naturales: conflicto social y ambiental a la luz del caso Awas Tingni”, Revista Conflicto Social, v.5, n. 7 (2012), pp. 90-113. 
La Barberá, MariaCaterina y Wences, Isabel, "La 'discriminación de género' en la jurisprudencia de la Corte Interamericana de Derechos Humanos: hacia categorías y medidas transformativas", Andamios. Revista de investigación social, v.17, n. 42 (2020), pp. 59-87.

Nash Rojas, Claudio, "La interpretación culturalmente sensible de los derechos humanos", en Víctor Bazán y Claudio Nash Rojas (eds.), Derechos fundamentales 4. Pluralismo jurídico, Bogotá, Editorial Universidad del Rosario, 2014.

Russo, Anna Margherita y Wences, Isabel, "De los derechos de los 'miembros de las comunidades' a los derechos de la 'comunidad y sus miembros' la diversidad cultural y el reconocimiento de la propiedad colectiva de los pueblos indígenas en la Corte Interamericana de Derechos Humanos", en Pablo Santolaya e Isabel Wences (eds.), La América de los Derechos, Madrid, Centro de Estudios Políticos y Constitucionales, 2016.

Stavenhagen, Rodolfo, "La jurisprudencia de la Corte Interamericana de Derechos Humanos en materia de derechos de los pueblos indígenas", Cuadernos Observatorio Pueblos Indígenas (Puno, Perú), n. 1. (2010), pp. 61-99.

Sauca, José María, Identidad y derecho. Nuevas perspectivas para viejos debates, Valencia, Tirant lo Blanch, 2010.

Wences, Isabel, "Reconocimiento y derecho a la diferencia de los pueblos indígenas de América Latina", en Juan Ramón de la Fuente y Pedro Pérez Herrero (coords.), El reconocimiento de las diferencias Estados, naciones e identidades en la globalización, Madrid, Universidad de Alcalá y Marcial Pons, 2016. 
